\title{
Pembelokan Cahaya Dalam Ruang Waktu Kerr-Einsten
}

\author{
Hasanuddin* \\ *Jurusan Fisika FMPA Universitas Tanjungpura, \\ e-mail:f_h45an@yahoo.com
}

\begin{abstract}
Abstrak
Dalam paper ini, diturunkan persamaan geodesik null dalam ruang waktu Kerr-Einstein empat dimensi dengan menggunakan prinsip bahwa setiap simetri dalam metrik berkaitan dengan vektor Killing. Dari persamaan geodesik null diperoleh sudut pembelokan cahaya di sekitar lubang hitam berotasi dengan menggunakan integral numerik. Berdasarkan hasil perhitungan numerik diperoleh bahwa untuk parameter dampak yang kecil maka sudut pembelokan cahaya sangat bergantung pada momentum sudut lubang hitam.
\end{abstract}

Kata Kunci: pembelokan cahaya, ruang waktu Kerr-Einstein, lubang hitam

\section{Pendahuluan}

Salah satu solusi eksak dalam Relativitas Umum adalah solusi Schwarzschild yang menggambarkan ruang waktu di sekitar lubang hitam yang tidak berotasi dan tidak bermuatan (Schwarzschild, 1916). Dengan menggunakan solusi ini dapat diprediksi sudut pembelokan cahaya bintang di sekitar matahari. Hasil ini sesuai dengan hasil eksperimen sehingga dapat membuktikan kebenaran teori Relativitas Umum.

Beberapa benda angkasa tidak hanya diam terhadap pusatnya tetapi berotasi pada sumbunya. Rotasi distribusi massa benda angkasa mempengaruhi ruang waktu di sekitarnya (Kerr, 1963). Solusi eksak, umum, dan unik yang menggambarkan ruang waktu di sekitar lubang hitam yang berotasi adalah solusi Kerr-Einstein.

Solusi ini sangat penting karena Relativitas Umum banyak diaplikasikan dalam kosmologi dan astrofisika. Selain itu, pengamatan terhadap orbit bintang mengelilingi pusat galaksi mengindikasikan bahwa ruang waktu di sekitar sumber radio Sgr $A^{*}$, yang merupakan kandidat lubang hitam dengan massa 3,6 juta kali massa matahari memiliki parameter Kerr $a=0,52$ (Genzel, 2003). Nilai ini merupakan setengah dari nilai maksimum parameter Kerr (Bardeen, dkk, 2001). Parameter Kerr memiliki arti fisis sebagai momentum sudut per satuan massa lubang hitam.

Kraniotis, 2012, telah menurunkan persamaan geodesik null dengan memecahkan persamaan differensial
Hamilton-Jacobi dalam metrik Kerr- (anti)de Sitter. Dalam papernya, perhitungan sudut pembelokan cahaya dihitung dengan menggunakan fungsi hipergeometrik Lauricella keempat dengan tiga variabel dan fungsi hipergeometrik Appel pertama dengan dua variabel.

Dengan motivasi tersebut, dalam paper ini diturunkan persamaan geodesik dengan menggunakan prinsip bahwa setiap simetri dalam metrik berkaitan dengan vektor Killing. Besar sudut pembelokan cahaya dihitung dengan cara yang lebih sederhana yaitu dengan menggunakan integral numerik.

\section{Landasan Teori}

Ruang waktu di sekitar lubang hitam berotasi dan tidak bermuatan dapat dideskripsikan oleh solusi Kerr-Einstein. Solusi ini dapat dinyatakan dengan elemen garis dalam koordinat Boyer-Lindquist sebagai berikut (Chandrasekhar, 1992)

$$
\begin{aligned}
& d \mathrm{~s}^{2}=\frac{\rho^{2} \Delta \Delta_{o}}{\Xi^{2} \sin ^{2} \theta}(d t)^{2} \\
& -\frac{\Xi^{2} \sin ^{2} \theta}{\rho^{2}}\left(d \varphi-\frac{2 a M r-\frac{\Lambda}{3}\left(r^{2}+a^{2}\right) \rho^{2} a}{\Xi^{2}} d t\right)^{2} \\
& -\frac{\rho^{2}}{\Delta_{r}}(d r)^{2}-\frac{\rho^{2} \sin ^{2} \theta}{\Delta_{\theta}}(d \theta)^{2} \\
& \text { dengan } \\
& \Delta_{r}=\frac{1}{3} \Lambda r^{2}\left(r^{2}+a^{2}\right)+r^{2}-2 M r+a^{2}
\end{aligned}
$$




$$
\begin{gathered}
\Delta_{\theta}=\left(1-\frac{1}{3} \Lambda a^{2} \cos ^{2} \theta\right) \sin ^{2} \theta \\
\rho^{2}=r^{2}+a^{2} \cos ^{2} \theta \\
\Xi^{2}=\left(r^{2}+a^{2}\right)^{2}\left(1-\frac{1}{3} a^{2} \cos ^{2} \theta\right)-\Delta a^{2} \sin ^{2} \theta
\end{gathered}
$$

Parameter $M$ memiliki arti fisis sebagai massa lubang hitam dan parameter $a$ memiliki arti fisis sebagai momentum sudut persatuan massa lubang hitam.

Lintasan cahaya atau foton dapat dianalisis dengan menyelesaikan persamaan geodesik untuk setiap koordinat. Tetapi, diperlukan waktu yang cukup lama untuk menyelesaikan persamaan tersebut dengan metode ini. Pendekatan lain untuk mempelajari lintasan cahaya dalam ruang waktu Kerr-Einstein adalah berdasarkan vektor Killing. Sebagaimana telah diketahui bahwa setiap simetri dalam metrik berkaitan dengan sebuah vektor Killing. Besaran kekal yang berhubungan dengan gerak partikel dapat ditentukan dengan membentuk perkalian titik antara vektor Killing dengan vektor kecepatan-4 dari partikel foton (McMahon, 2006).

Vektor kecepatan-4 dari partikel foton dalam ruang waktu Kerr-Einstein memiliki komponen

$$
\vec{v}=\left(\frac{d t}{d \tau}, \frac{d \varphi}{d \tau}, \frac{d r}{d \tau}, \frac{d \theta}{d \tau}\right)=(\dot{t}, \dot{\varphi}, \dot{r}, \dot{\theta})
$$

dengan $\tau$ adalah waktu yang diukur oleh pengamat yang diam. Vektor kecepatan-4 memenuhi kondisi (Hartle, 2003)

$$
\vec{v} \cdot \vec{v}=g_{\alpha \beta} v^{\alpha} v^{\beta}=0
$$

Jika lintasan cahaya dibatasi dalam satu bidang yaitu dipilih bidang ekuator dengan $\theta=\pi / 2$, maka $\dot{\theta}=0$. Untuk metrik KerrEinstein, persamaan (7) menjadi

$$
\begin{aligned}
& \frac{\Delta_{r}-a^{2} \Delta_{\theta}}{\rho^{2}} \dot{t}^{2}+2 a \frac{\left(r^{2}+a^{2}\right) \Delta_{\theta}-\Delta_{r}}{\rho^{2}} \dot{t} \dot{\varphi} \\
& -\frac{\left(r^{2}+a^{2}\right)^{2}\left(1-\frac{1}{3} a^{2} \mu^{2}\right)}{\rho^{2}} \dot{\varphi}^{2}-\frac{\rho^{2}}{\Delta_{r}} \dot{r}^{2}=0
\end{aligned}
$$

dengan beberapa besaran tereduksi menjadi

$$
\Delta_{\theta}=1 \quad \text { dan } \rho^{2}=r^{2}
$$

Metrik Kerr-Einstein tidak bergantung pada waktu $t$ dan sudut $\varphi$. Oleh karena itu, dapat didefinisikan dua buah vektor Killing, yaitu

$$
\vec{\xi}=(1,0,0,0) \quad \text { dan } \vec{\eta}=(0,1,0,0)
$$

Besaran kekal yang berhubungan dengan vektor Killing $\vec{\xi}$ adalah rapat energi

$$
\begin{aligned}
E & =-\vec{\xi} \cdot \vec{v} \\
& =-\frac{\Delta_{r}-a^{2}}{r^{2}} \dot{t}-a \frac{\left(r^{2}+a^{2}\right)-\Delta_{r}}{r^{2}} \dot{\varphi}
\end{aligned}
$$

Sedangkan besaran kekal yang berhubungan dengan vektor Killing $\vec{\eta}$ adalah rapat energi momentum sudut

$$
\begin{aligned}
L & =-\vec{\eta} \cdot \vec{v}=a \frac{\left(r^{2}+a^{2}\right)-\Delta_{r}}{r^{2}} \dot{t} \\
& -\frac{\left(r^{2}+a^{2}\right)^{2}\left(1-\frac{\Lambda}{3} a^{2} \mu^{2}\right)-\Delta_{r} a^{2}}{r^{2}} \dot{\varphi}
\end{aligned}
$$

Besaran $E$ and $L$ dinamakan juga sebagai konstanta gerak partikel foton (cahaya).

Dengan menggunakan nilai konstanta gerak di atas maka persamaan (8) dapat ditulis menjadi

$$
\begin{aligned}
& \frac{\left(r^{2}+a^{2}\right)^{2}-\Delta_{r} a^{2}}{r^{2} \Delta_{r}} \\
& {\left[E-\frac{2 M r a-\frac{\Lambda}{3}\left(r^{2}+a^{2}\right) r^{2} a}{\left(r^{2}+a^{2}\right)^{2}-\Delta_{r} a^{2}} L\right]^{2}} \\
& -\frac{r^{2}}{\left(r^{2}+a^{2}\right)^{2}-\Delta_{r} a^{2}}-\frac{r^{2}}{\Delta_{r}} \dot{r}^{2}=0
\end{aligned}
$$

dengan $\dot{r}$ adalah turunan pertama $r$ terhadap suatu parameter $\lambda$. Persamaan (13) dapat ditulis dalam bentuk yang lebih sederhana yaitu

$$
\dot{r}^{2}=r^{-4} R(r ; a, M, \Lambda)
$$

dengan $R(r ; a, M, \Lambda)$ adalah fungsi dari $r$ dan bergantung pada parameter $a, M$, dan $\Lambda$ yang didefinisikan sebagai

$$
R=\left[\left(r^{2}+a^{2}\right) E-a L\right]^{2}-\Delta_{r}(a E-L)^{2}
$$

Dengan memperkenalkan parameter dampak $l$ sebagai berikut

$$
l=L / E
$$

dan variabel baru $u=1 / r$, persamaan (14) dapat ditulis dalam bentuk

$$
u^{-4} \dot{u}^{2}=E^{2} B(u)
$$

dengan $B(u)$ merupakan suatu polinomial kubik

$$
\begin{aligned}
& B(u)=1+\left(a^{2}-l^{2}\right) u^{2} \\
& +2 M(a-l)^{2} u^{3}-(a-l)^{2} \frac{\Lambda}{3}\left(1+u^{2}\right)
\end{aligned}
$$


sementara $\dot{\varphi}$ dapat ditulis dalam bentuk

$$
\dot{\varphi}=u^{2} \frac{A(u)}{D(u)}
$$

dengan $A(u)$ and $D(u)$ merupakan fungsi yang didefinisikan sebagai

$$
\begin{gathered}
A(u)=E[l+2 M(a-l) u \\
\left.-(a-l) \frac{\Lambda}{3}\left(\frac{1}{u^{2}}+a^{2}\right)\right] \\
D(u)=1+a^{2} u^{2}-2 M u+\frac{\Lambda}{3}\left(\frac{1}{u^{2}}+a^{2}\right)
\end{gathered}
$$

Akhirnya, didapat persamaan geodesik null untuk lintasan foton di bidang ekuator dalam ruang waktu Kerr-Einstein

$$
\frac{d \varphi}{d u}=\frac{A(u)}{D(u) \sqrt{B(u)}}
$$

\section{Metodologi}

Metodologi yang digunakan dalam penelitian ini adalah studi literatur dan komputasi numerik. Beberapa literatur ditelaah sehingga perumusan matematis dalam teori tersebut dipahami dengan baik. Selain itu digunakan juga teknik komputasi numerik yang dibantu dengan menggunakan software Mathematica ${ }^{\circledR}$ Bagan alir penelitian dapat dilihat pada gambar berikut:

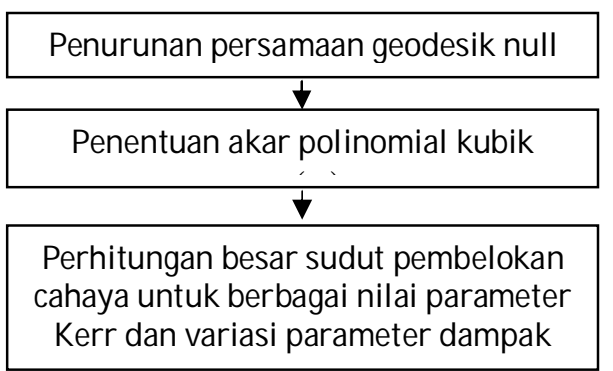

Gambar 1. Bagan alir penelitian

\section{Hasil dan Diskusi}

Untuk menentukan besar sudut pembelokan cahaya di sekitar lubang hitam maka diperlukan integral

$$
\Delta \varphi=2 \int_{0}^{u_{2}} d \varphi
$$

dengan $u_{2}$ adalah salah satu akar dari polinomial $B(u)$. Akar-akar polinomial tersebut dapat diurutkan sebagai $u_{1}<0<u_{2}<u_{3}$.

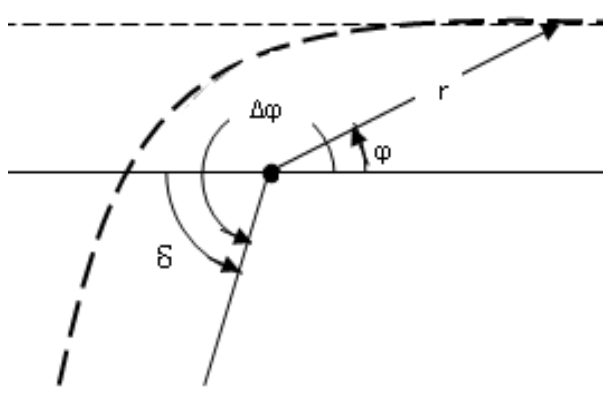

Gambar 2. Diagram skematik pembelokan cahaya .

Jika konstanta kosmologi sama dengan nol $(\Lambda=0)$, maka polinomial kubik $B(u)$ akan menjadi

$$
\begin{aligned}
B(u) & =1+\left(a^{2}-l^{2}\right) u^{2} \\
& +2 M(a-l)^{2} u^{3} \text { untuk } \Lambda=0
\end{aligned}
$$

Untuk parameter Kerr $a=0,52 G M / c^{2}$ maka akar-akar dari $B(u)$ untuk berbagai parameter dampak adalah

Tabel 1. Akar-akar $B(u)$ untuk

$$
a=0,52 G M / c^{2} \text {. }
$$

\begin{tabular}{|c|c|c|c|}
\hline $\begin{array}{c}l \text { dalam } \\
G M / c^{2}\end{array}$ & $u_{1}$ & $u_{2}$ & $u_{3}$ \\
\hline 5 & $-0,17721$ & 0,26723 & 0,52605 \\
\hline 10 & $-0,09269$ & 0,11209 & 0,53545 \\
\hline 15 & $-0,06309$ & 0,07167 & 0,52734 \\
\hline 20 & $-0,04788$ & 0,05272 & 0,52186 \\
\hline 40 & $-0,02442$ & 0,02565 & 0,51195 \\
\hline
\end{tabular}

Untuk parameter Kerr $a=0,9939 G M / c^{2}$ maka akar-akar dari $B(u)$ untuk berbagai parameter dampak adalah

Tabel 2. Akar-akar $B(u)$ untuk

\begin{tabular}{|c|c|c|c|}
\multicolumn{5}{|c|}{$a=0,9939 G M / c^{2}}$. \\
\hline $\begin{array}{c}l \text { dalam } \\
G M / c^{2}\end{array}$ & $u_{1}$ & $u_{2}$ & $u_{3}$ \\
\hline 5 & $-0,18292$ & 0,25012 & 0,68089 \\
\hline 10 & $-0,09357$ & 0,11112 & 0,59281 \\
\hline 15 & $-0,06338$ & 0,07143 & 0,56291 \\
\hline 20 & $-0,04801$ & 0,05263 & 0,54767 \\
\hline 40 & $-0,02444$ & 0,02564 & 0,52428 \\
\hline
\end{tabular}

Sudut pembelokan cahaya $\delta$ dapat diperoleh melalui persamaan 


$$
\delta=\Delta \varphi-\pi
$$

Perhitungan integral dalam persamaan (23) dapat dibantu dengan menggunakan fungsi NIntegrate dalam software Mathematica ${ }^{\circledR}$. Hasil prediksi besar sudut pembelokan cahaya dapat dituliskan dalam tabel-tabel berikut:

Tabel 3. Hasil prediksi sudut pembelokan cahaya untuk $a=0,52 \mathrm{GM} / \mathrm{c}^{2}$.

\begin{tabular}{|c|c|c|}
\hline $\begin{array}{c}l \text { dalam } \\
G M / c^{2}\end{array}$ & $\begin{array}{c}\Delta \varphi \text { dalam } \\
\text { rad }\end{array}$ & $\begin{array}{c}\delta \text { dalam } \\
\text { rad }\end{array}$ \\
\hline 5 & 4,988620 & 1,847027 \\
\hline 10 & 3,673800 & 0,532207 \\
\hline 15 & 3,456700 & 0,315107 \\
\hline 20 & 3,367100 & 0,225507 \\
\hline 40 & 3,244660 & 0,103067 \\
\hline
\end{tabular}

Tabel 4. Hasil prediksi sudut pembelokan cahaya untuk $a=0,9939 \mathrm{GM} / \mathrm{c}^{2}$.

\begin{tabular}{|c|c|c|}
\hline $\begin{array}{c}l \text { dalam } \\
G M / c^{2}\end{array}$ & $\begin{array}{c}\Delta \varphi \text { dalam } \\
\text { rad }\end{array}$ & $\begin{array}{c}\delta \text { dalam } \\
\text { rad }\end{array}$ \\
\hline 5 & 4,457420 & 1,315827 \\
\hline 10 & 3,636340 & 0,494747 \\
\hline 15 & 3,444980 & 0,303387 \\
\hline 20 & 3,361300 & 0,219707 \\
\hline 40 & 3,243460 & 0,101867 \\
\hline
\end{tabular}

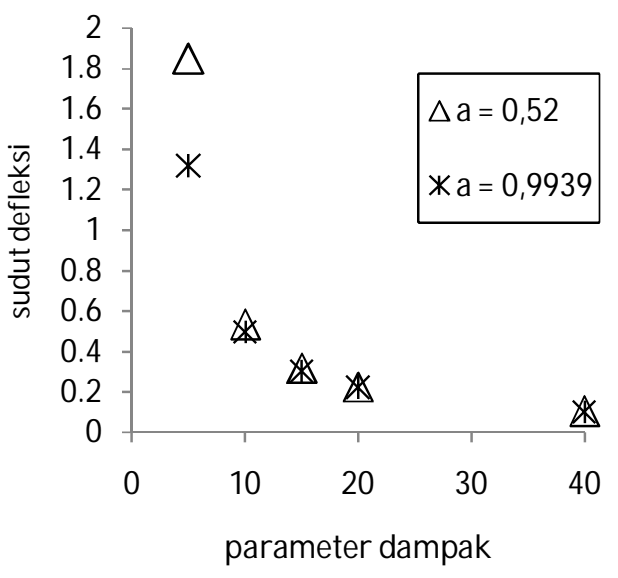

Gambar 3. Sudut pembelokan cahaya untuk berbagai nilai parameter dampak dan dua nilai parameter Kerr.

\section{Kesimpulan}

Berdasarkan hasil perhitungan numerik sudut pembelokan cahaya di sekitar lubang hitam, didapatkan bahwa untuk parameter dampak yang kecil maka sudut pembelokan cahaya sangat bergantung terhadap parameter kerr. Dengan kata lain, besar sudut pembelokan cahaya sangat bergantung terhadap momentum sudut persatuan massa dari lubang hitam. Hasil ini sangat berguna dalam studi lensa gravitasi dengan lubang hitam sebagai lensa.

\section{Pustaka}

Bardeen, J.M., Press, W.M., dan Teukolsky, S.A., Rotating black holes: Locally, nonrotating frames, energy extraction and scaar synchrotron radiation, Astrophys. J. Volume 178, 1972, 347-369.

Chandrasekhar, S., 1992,The Mathematical Theory of Black Holes, Oxford University Press, Oxford.

Genzel, Near-Infrared flares from accreting gas around the supermassive black hole at the Galactic Centre, Nature, Volume 425, 2003, 934-937.

Hartle, J.B., 2003, Gravity: an Introduction to Einstein's General Relativity, Pearson Education, Inc., San Francisco.

Kerr, R.P., Gravitational filed of a spinning mass as an example of algebraically special metrics, Phys. Rev. Letters 11, 1963, 237.

Kraniotis, G.V., Frame-dragging and bending of Light in Kerr and Kerr-(anti) de Sitter spacetimes. 2012 [arXiv:grqc/ 0507056v3].

McMahon, D. 2006, Relativity Demistified, The McGraw-Hill Companies Inc, New York.

Schwarzschild, K., Über das Gravitationfeld eines Massenpunktes nach der Einsteinschen Theorie. Sitzungsberichte der königlich Preussischen Akademie der Wissenschaften zu Berlin, Phys.- Math. Klasse, 1916, 189-196. 